\title{
A Probabilistic Linguistic Multiple Attribute Decision Making Based on a New Correlation Coefficient Method and its Application in Hospital Assessment
}

\author{
Dandan Luo ${ }^{1}$, Shouzhen Zeng ${ }^{1,2,3, *}$ and Ji Chen ${ }^{2}$ \\ 1 School of Business, Ningbo University, Ningbo 315211, China; 1811021037@nbu.edu.cn \\ 2 College of Statistics and Mathematics, Zhejiang Gongshang University, Hangzhou 310018, China; \\ chenji810404@zjgsu.edu.cn \\ 3 School of Management, Fudan University, Shanghai 200433, China \\ * Correspondence: zengshouzhen@nbu.edu.cn
}

Received: 2 February 2020; Accepted: 28 February 2020; Published: 4 March 2020

\begin{abstract}
The probabilistic linguistic term set (PLTS) is a newly emerging mathematical tool for handling uncertainties. It is considered a useful extension of linguistic term sets associated with probability information and can improve the effectiveness of multiple attribute decision making (MADM). This paper proposes a new PLTS correlation coefficient and addresses its usefulness in MADM problems. For achieving this aim, some new concepts of mean, variance, and covariance of the PLTS are first proposed. Moreover, a novel PLTS Pearson correlation coefficient is defined to overcome the shortcomings of the existing methods, whose significant feature is that it lies in the interval $[-1,1]$, which makes it more effective in reflecting the negative and positive correlation between PLTSs. A weighted PLTS Pearson correlation coefficient is further defined to consider the importance of attribute weights and expand the scope of application. Then, a relative PLTS closeness coefficient is constructed based on the developed Pearson correlation coefficient, and based on which, a Pearson correlation-based TOPSIS (technique for order of preference by similarity to ideal solution) approach for MADM problems is developed. Finally, the effectiveness as well as the applicability of the developed method are illustrated through numerical examples and comparative analysis.
\end{abstract}

Keywords: probabilistic linguistic term set; TOPSIS; Pearson correlation coefficient; multiple attribute decision making; hospital assessment

\section{Introduction}

The probabilistic linguistic term set (PLTS) [1] is a kind of linguistic term set that can reflect the different importance of all possible evaluation of a particular object. This is a very useful tool in dealing with hesitant fuzzy linguistic multiple attribute decision making (MADM) problems. It can not only improve the diversity and flexibility of linguistic expression, but also reflect the preference information of decision makers for these linguistic variables. Recently, the PLTS decision making problems have attracted increasing attention from many scholars, and the construction of the theoretical basis and decision-making methods concerning the PLTS have been perfected and enriched.

In terms of the PLTS theoretical basis construction, many researchers discussed the aspects of relevant algorithms [1,2], distance and similarity measures [3,4], possibility degree measures $[5,6]$, and information entropy measures [7]. Many scholars also extended some classic decision-making methods to PLTS situations, and explored their usefulness in decision making areas [1,8-15]. Several scholars have successfully explored the application of the technique for order of preference by similarity to ideal solution (TOPSIS) in the PLTS environment [1,16-18]. 
The Pearson correlation coefficient is an important tool to reflect the degree of correlation between two variables or sets [19]. Up to now, the research of correlation coefficients has been extended from classic crisp numbers to several uncertain situations [20-29]. The value of a correlation coefficient generally lies in the interval $[-1,1]$ in the statistical area. For this reason, the correlation coefficient cannot be directly applied with TOPSIS methods as the later can only deal with the information measures with positive values like distance measures.

To solve this issue and extend the application scope of correlation coefficients, Chen [30] proposed a correlation-based TOPSIS model for an interval-valued Pythagorean fuzzy MADM framework, in which Chen uses correlation coefficients instead of distance measures to construct a new closeness coefficient. Later Jin et al. [31] extended Chen's work to solve MADM problems within picture fuzzy situations. Sun et al. [32] proposed an innovative TOPSIS method based on correlation coefficients under hesitant fuzzy environments. However, apart from the mentioned distance-based TOPSIS model [1], the correlation-based TOPSIS has not been yet fully investigated for practical MADM problems in the PLTS environment. Thus, this article aims to propose a novel TOPSIS method based on a new PLTS correlation coefficient to address the PLTS MADM problems.

In order to measure the correlated relationship between PLTSs, Mao et al. [12] first proposed the PLTS correlation coefficient. However, the value of the correlation coefficient proposed by Mao et al. [12] lies in $[0,1]$, and is thus not consistent with the correlation coefficient in statistics that lies in $[-1,1]$. Lin et al. [33] then introduced a new correlation coefficient on the basis of the mean and variance of the PLTSs, which conforms to the correlation coefficient in statistics that lies in $[-1,1]$. However, this correlation coefficient actually measures the correlated relationship between the PLTS vectors, and it is a partial correlation coefficient of the mean type. As long as the score values of each pair in two PLTS vectors are equal, and no matter what the PLTS vectors is, the correlation coefficients between the two PLTS vectors are always equal, which will lead to a biased result in practical applications.

For solving these problems, in this paper, a new method for calculating the mean, variance, and covariance of the PLTS is first proposed by specifying the linguistic term and corresponding probability for each element in PLTS, and based on which, a new PLTS Pearson correlation coefficient is defined to eliminate the major defects within the current methods. The value of the proposed PLTS correlation coefficient lies in the interval $[-1,1]$ conforming to the statistics that are superior in discrimination. This is more convincing than the previous correlation coefficient when considering the characteristics of all elements in each PLTS. The weighted Pearson correlation coefficient for PLTSs is further proposed to highlight the importance of the attributes in MADM problems. Consequently, a PLTS Pearson correlation-based TOPSIS method for MADM is constructed based on the presented weighted correlation coefficient, which is used to construct a new comprehensive closeness coefficient for ranking all alternatives.

The remainder of this paper is organized as follows: In Section 2, we briefly introduce some basic conceptions of PLTS, the comparison laws of PLTS, and some existing correlation coefficients for PLTSs. In Section 3, a new ranking rule of PLTS is proposed. Additionally, a new PLTS Pearson correlation coefficient based on the new mean, variance, and covariance of the PLTS is presented. A novel TOPSIS method based on the defined correlation coefficient is developed in Section 4. A case concerning hospital assessment is provided in Section 5. Moreover, some relevant comparisons are performed in Section 6. The paper ends with some concluding remarks and future challenges in Section 7.

\section{Preliminaries}

We will briefly introduce some basic conceptions concerning the PLTS.

Definition 1 ([1]). Let $S=\left\{s_{\alpha} \mid \alpha=0,1,2, \cdots, \tau\right\}$ be a linguistic term set (LTS), a PLTS is defined as:

$$
L P=\left\{L^{(l)}\left(p^{(l)}\right) \mid L^{(l)} \in S, p^{(l)} \geq 0, l=1,2, \cdots, \# L P, \sum_{l=1}^{\# L P} p^{(l)} \leq 1\right\}
$$


where $L^{(l)}\left(p^{(l)}\right)$ is the linguistic term $L^{(l)}$ corresponding to the probability $p^{(l)}$, and \#LP is the number of all different linguistic terms in $L P$.

Definition 2 ([1]). Given a PLTS LP with $\sum_{l=1}^{\# L P} p^{(l)}<1$, then the normalized PLTS LP is defined by

$$
\dot{L P}=\left\{L^{(l)}\left(\dot{p}^{(l)}\right) \mid l=1,2, \cdots, \# \dot{L P}\right\}
$$

where $\dot{p}^{(l)}=p^{(l)} / \sum_{k=1}^{\# P_{P}} p^{(l)}, l=1,2, \cdots, \#$, $\dot{P}$.

Definition 3 ([1]). Let $L P_{1}$ and $L P_{2}$ be any two PLTSs, $L P_{i}=\left\{L_{i}^{(l)}\left(p_{i}^{(l)}\right) \mid l=1,2, \cdots, \# L P_{i}\right\}(i=1,2)$, and let $\# L P_{1}$ and $\# L P_{2}$ be the number of linguistic terms in $L P_{1}$ and $L P_{2}$ respectively. If $\# L P_{1}>\# L P_{2}$, then we will add $\# L P_{1}-\# L P_{2}$ linguistic terms to $L P_{2}$ so that the values of linguistic terms in $L P_{1}$ and $L P_{2}$ are equal. The added linguistic terms are the smallest ones in $\mathrm{LP}_{2}$, and the probabilities of all the added linguistic terms are equal to zero.

Definition 4 ([1]). Let $L P=\left\{L^{(l)}\left(p^{(l)}\right) \mid l=1,2, \cdots \# L P\right\}$ be a PLTS, and $s^{(l)}$ be the subscript of linguistic term $L^{(l)}$. Then the score for $L P$ is given as follows:

$$
E(L P)=s_{\bar{\alpha}}
$$

where $\bar{\alpha}=\sum_{k=1}^{\# L P}\left(s^{(l)} p^{(l)}\right) / \sum_{k=1}^{\# L P} p^{(l)}$

Definition 5 ([1]). Let $L P=\left\{L^{(l)}\left(p^{(l)}\right) \mid l=1,2, \cdots \# L P\right\}$ be a PLTS, and $s^{(l)}$ be the subscript of linguistic term $L^{(l)}$, and $E(L P)=s_{\bar{\alpha}}$, where $\bar{\alpha}=\sum_{l=1}^{\# L P}\left(s^{(l)} p^{(l)}\right) / \sum_{l=1}^{\# L P} p^{(l)}$. Then the deviation degree of LP is:

$$
\delta(L P)=\left(\sum_{l=1}^{\# L P}\left(p^{(l)}\left(s^{(l)}-\bar{\alpha}\right)\right)^{2}\right)^{1 / 2} / \sum_{l=1}^{\# L P} p^{(l)} .
$$

Definition 6 ([1]). Let $L P_{1}$ and $L P_{2}$ be any two PLTSs, Then,

(1) if $E\left(L P_{1}\right)>E\left(L P_{2}\right)$, then $L P_{1}>L P_{2}$;

(2) if $E\left(L P_{1}\right)=E\left(L P_{2}\right)$, then

(a) if $\delta\left(L P_{1}\right)>\delta\left(L P_{2}\right)$, then $L P_{1}<L P_{2}$;

(b) if $\delta\left(L P_{1}\right)=\delta\left(L P_{2}\right)$, then $L P_{1} \sim L P_{2}$.

Definition 7 ([12]). Let $\widetilde{L P}_{1}$ and $\widetilde{L P}_{2}$ be any two order PLTSs, $\widetilde{L P}_{i}=\left\{\widetilde{L}_{i}^{(l)}\left(\widetilde{p}_{i}^{(l)}\right) \mid l=1,2, \cdots, \# \widetilde{L P}_{i}\right\}(i=1,2)$, $\# \widetilde{L P}_{1}=\# \widetilde{L P}_{2}$, then the correlation coefficient between $\widetilde{L P}_{1}$ and $\widetilde{L P}_{2}$ is given as follows:

$$
\kappa\left(\widetilde{L P}_{1}, \widetilde{L P}_{2}\right)=\frac{\sum_{k=1}^{\# \widetilde{L P}_{1}}\left(\widetilde{s}_{1}^{(l)} \tilde{p}_{1}^{(l)}\right)\left(\tilde{s}_{2}^{(l)} \widetilde{p}_{2}^{(l)}\right)}{\sqrt{\sum_{l=1}^{\# \widetilde{L P}_{1}}\left(\widetilde{s}_{1}^{(l)} \widetilde{p}_{1}^{(l)}\right)^{2}} \sqrt{\sum_{l=2}^{\# \widetilde{L P}_{2}}\left(\widetilde{s}_{2}^{(l)} \widetilde{p}_{2}^{(l)}\right)^{2}}} .
$$


Definition 8 ([33]). For a set of criteria $C=\left\{c_{1}, c_{2}, \cdots, c_{n}\right\}$, let $L_{1}=\left\{\left\langle c_{i}, L P_{1 c_{i}}\right\rangle \mid c_{i} \in C\right\}$ as well as $L_{2}=$ $\left\{\left\langle c_{i}, L P_{2 c_{i}}\right\rangle \mid c_{i} \in C\right\}$ be any two different collections of PLTSs defined in the LTS $S=\left\{s_{\alpha} \mid \alpha=0,1,2, \cdots, \tau\right\}$, whereas $L P_{1 c_{i}}=\left\{L_{1 c_{i}}^{(l)}\left(p_{1 c_{i}}^{(l)}\right) \mid l=1,2, \cdots, \# L P_{1 c_{i}}\right\}$ and $L P_{2 c_{i}}=\left\{L_{2 c_{i}}^{(l)}\left(p_{2 c_{i}}^{(l)}\right) \mid l=1,2, \cdots, \# L P_{2 c_{i}}\right\}$, then the correlation coefficient between $L_{1}$ and $L_{2}$ is defined as follows:

$$
\begin{aligned}
& \xi\left(L_{1}, L_{2}\right)=\frac{C\left(L_{1}, L_{2}\right)}{\left[\operatorname{Var}\left(L_{1}\right) \cdot \operatorname{Var}\left(L_{2}\right)\right]^{1 / 2}}
\end{aligned}
$$

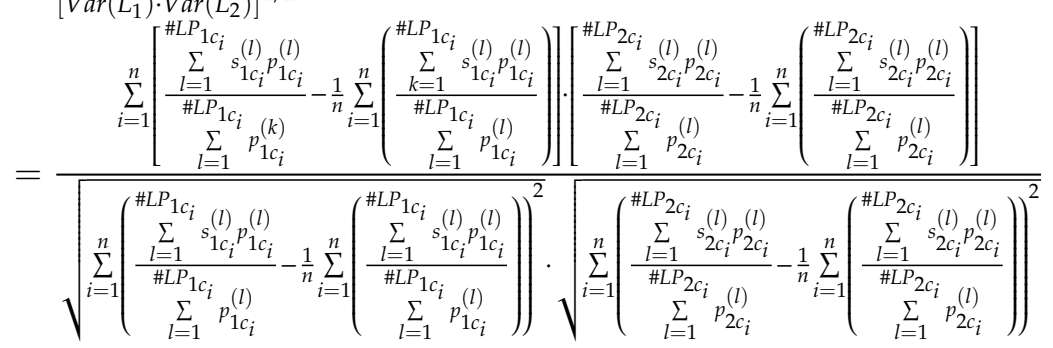

\section{Pearson Correlation Coefficient for PTLSs}

We observe from definition 7 that the PLTS correlation coefficient introduced by Mao et al. [12] is always positive, which does not conform to the correlation coefficient in statistics that lies in $[-1,1]$. Thus, it fails to describe the negative correlated relationship between PLTSs. In definition 8 , although the correlation coefficient defined by Lin et al. [33] is bounded in $[-1,1]$, the mean and variance of PLTSs used in the correlation coefficient are not the true sense of the PLTS mean and the PLTS variance as they ignore the importance of each element in the PLTS, which actually reflects the correlated relationship between two PLTS vectors rather than two PLTSs. It is only a mean type of correlation coefficient. The correlation coefficient in statistics is defined as "normalized covariances of random variables". Motivated by this idea, next, we redefine the mean, variance, and covariance of the PLTS by specifying the linguistic variables and corresponding probabilistic information for each element in PLTS, and based on which, a new PLTS Pearson correlation coefficient is defined, with bounds in the interval $[-1,1]$.

First, we point out that the ranking rule of PLTS proposed in Pang et al. [1] fails when there are two or more elements in a PLTS with same values of $s^{(l)} p^{(l)}$. Giving a PLTS $L(p)=\left\{s_{2}(0.4), s_{3}(0.4), s_{6}(0.2)\right\}$ for instance, $s^{(2)} p^{(2)}=s^{(3)} p^{(3)}=1.2$, which shows that these two elements cannot be arranged by the method introduced in [1]. A new ranking rule to address this shortcoming, is defined below:

Definition 9. Given a PLTS $L P=\left\{L^{(l)}\left(p^{(l)}\right) \mid l=1,2, \cdots \# L P\right\}$ :

(1) If all elements in the PLTS have different values of $s^{(l)}$, then $L^{(l)}\left(p^{(l)}\right)$ are arranged in accordance with the values of $s^{(l)}(l=1,2, \cdots \# L P)$ directly.

(2) If there exist two or more elements with same values of $s^{(l)}$, then arrange $L^{(l)}\left(p^{(l)}\right)$ according to descending order of $p^{(l)}(l=1,2, \cdots \# L P)$.

Definition 10. Let $L P=\left\{L^{(l)}\left(p^{(l)}\right) \mid l=1,2, \cdots \# L P\right\}$ be a PLTS, then, the mean of the PLTS LP is given as follows:

$$
\overline{L P}=\frac{1}{\# L P} \sum_{l=1}^{\# L P} s^{(l)} \cdot p^{(l)} .
$$


Definition 11. Let $L P=\left\{L^{(l)}\left(p^{(l)}\right) \mid l=1,2, \cdots \# L P\right\}$ be a PLTS, then, the variance of the PLTS is defined as follows:

$$
\operatorname{Var}(L P)=\frac{1}{\# L P} \sum_{l=1}^{\# L P}\left(s^{(l)} \cdot p^{(l)}-\overline{L P}\right)^{2} .
$$

Definition 12. Let $L P_{1}$ and $L P_{2}$ be any two different PLTSs, in which $L P_{1}=\left\{L_{1}^{(l)}\left(p_{1}^{(l)}\right) \mid l=1,2, \cdots, \# L P_{1}\right\}$ and $L P_{2}=\left\{L_{2}^{(l)}\left(p_{2}^{(l)}\right) \mid l=1,2, \cdots, \# L P_{2}\right\}$. Then, the covariance between $L P_{1}$ and $L P_{2}$ can be defined as follows:

$$
C\left(L P_{1}, L P_{2}\right)=\frac{1}{k} \sum_{l=1}^{k}\left[s_{1}^{(l)} \cdot p_{1}^{(l)}-\overline{L P_{1}}\right]\left[s_{2}^{(l)} \cdot p_{2}^{(l)}-\overline{L P_{2}}\right]
$$

where $k=\# L P_{1}=\# L P_{2}$, and $s_{i}{ }^{(l)}$ be the subscript of the linguistic term $L_{i}{ }^{(l)}(i=1,2)$.

Definition 13. Let $L P_{1}$ and $L P_{2}$ be any two different PLTSs, in which $L P_{1}=\left\{L_{1}^{(l)}\left(p_{1}^{(l)}\right) \mid l=1,2, \cdots, \# L P_{1}\right\}$ and $L P_{2}=\left\{L_{2}^{(l)}\left(p_{2}^{(l)}\right) \mid l=1,2, \cdots, \# L P_{2}\right\}$. Then, the Pearson correlation coefficient for PLTSs can be defined as follows:

$$
\rho\left(L P_{1}, L P_{2}\right)=\frac{C\left(L P_{1}, L P_{2}\right)}{\left[\operatorname{Var}\left(L P_{1}\right) \cdot \operatorname{Var}\left(L P_{2}\right)\right]^{1 / 2}}=\frac{\sum_{l=1}^{k}\left[s_{1}^{(l)} \cdot p_{1}^{(l)}-\overline{L P_{1}}\right]\left[s_{2}^{(l)} \cdot p_{2}^{(l)}-\overline{L P_{2}}\right]}{\left[\sum_{l=1}^{k}\left(s_{1}^{(l)} \cdot p_{1}^{(l)}-\overline{L P_{1}}\right)^{2} \cdot \sum_{l=1}^{k}\left(s_{2}^{(l)} \cdot p_{2}^{(l)}-\overline{L P_{2}}\right)^{2}\right]^{1 / 2}} .
$$

It is noted that the numbers of elements in $L P_{1}$ and $L P_{2}$ shall be same respectively in definitions 12 and 13, i.e., $k=\# L P_{1}=\# L P_{2}$. If $\# L P_{1} \neq \# L P_{2}$, the short PLTS needs to be normalized according to the rules given in definition 3 so that $\# L P_{1}=\# L P_{2}$.

Theorem 1. The PLTS Pearson correlation coefficient $\rho\left(L P_{1}, L P_{2}\right)$ between $L P_{1}$ and $L P_{2}$ has following important properties:

$\begin{array}{ll}\text { (T1.1) } & \rho\left(L P_{1}, L P_{2}\right)=\rho\left(L P_{2}, L P_{1}\right) ; \\ \text { (T1.2) } & \rho\left(L P_{1}, L P_{1}\right)=1 ; \\ \text { (T1.3) } & -1 \leq \rho\left(L P_{1}, L P_{2}\right) \leq 1 .\end{array}$

Proof. The proofs for T1.1 and T1.2 are obvious from definition 13.

For the proof T1.3:

$$
\begin{aligned}
\left|C\left(L P_{1}, L P_{2}\right)\right| & =\left|\frac{1}{k} \sum_{l=1}^{k}\left[s_{1}^{(l)} \cdot p_{1}^{(l)}-\overline{L P_{1}}\right]\left[s_{2}^{(l)} \cdot p_{2}^{(l)}-\overline{L P_{2}}\right]\right| \\
& \leq \frac{1}{k} \sum_{l=1}^{k}\left|s_{1}^{(l)} \cdot p_{1}^{(l)}-\overline{L P_{1}}\right|\left|s_{2}^{(l)} \cdot p_{2}^{(l)}-\overline{L P_{2}}\right| .
\end{aligned}
$$


According to the Cauchy Schwartz inequality, we have:

$$
\begin{aligned}
\left|C\left(L P_{1}, L P_{2}\right)\right| & \leq \frac{1}{k} \sqrt{\sum_{l=1}^{k}\left|s_{1}^{(l)} \cdot p_{1}^{(l)}-\overline{L P_{1}}\right|^{2}} \cdot \sqrt{\sum_{l=1}^{k}\left|s_{2}^{(l)} \cdot p_{2}^{(l)}-\overline{L P_{2}}\right|^{2}} \\
& =\sqrt{\frac{1}{k} \sum_{l=1}^{k}\left|s_{1}^{(l)} \cdot p_{1}^{(l)}-\overline{L P_{1}}\right|^{2}} \cdot \sqrt{\frac{1}{k} \sum_{l=1}^{k}\left|s_{2}^{(l)} \cdot p_{2}^{(l)}-\overline{L P_{2}}\right|^{2}} \\
& =\sqrt{\operatorname{Var}\left(L P_{1}, L P_{1}\right)} \cdot \sqrt{\operatorname{Var}\left(L P_{2}, L P_{2}\right)}
\end{aligned}
$$

then, $\left|C\left(L P_{1}, L P_{2}\right)\right| \leq \sqrt{\operatorname{Var}\left(L P_{1}, L P_{1}\right)} \cdot \sqrt{\operatorname{Var}\left(L P_{2}, L P_{2}\right)}$, that is, $-1 \leq \rho\left(L P_{1}, L P_{2}\right) \leq 1$.

Example 1. Let $L P_{1}=\left\{s_{5}(0.2), s_{4}(0.4), s_{6}(0.2)\right\}$ and $L P_{2}=\left\{s_{4}(0.5), s_{5}(0.5)\right\}$ be two PLTSs defined in LTS $S=\left\{s_{1}, s_{2}, \cdots, s_{7}\right\}$. The calculating process of the Pearson correlation coefficient $\rho\left(L P_{1}, L P_{2}\right)$ is shown as follows:

(1) Normalize $L P_{1}$ and $L P_{2}$ as $\sum_{l=1}^{\# L P_{1}} p_{1}{ }^{(l)}<1$ and $\# L P_{1}>\# L P_{2}$ :

$$
L P_{1}^{\prime}=\left\{s_{6}(0.25), s_{5}(0.25), s_{4}(0.5)\right\}, L P_{2}^{\prime}=\left\{s_{5}(0.5), s_{4}(0.5), s_{4}(0)\right\} \text {. }
$$

(2) Calculate the means and variances of $L P_{1}^{\prime}$ and $L P_{2}^{\prime}$ by using Equations (7) and (8):

$$
\overline{L P_{1}^{\prime}}=1.583, \overline{L P_{2}^{\prime}}=1.5 ; \operatorname{Var}\left(L P_{1}^{\prime}\right)=0.097, \operatorname{Var}\left(L P_{2}^{\prime}\right)=1.167 \text {. }
$$

(3) Compute the covariance for $L P_{1}^{\prime}$ and $L P_{2}^{\prime}$ :

$$
C\left(L P_{1}^{\prime}, L P_{2}^{\prime}\right)=-0.2917
$$

(4) Calculate the Pearson correlation coefficient by using Equation (10):

$$
\rho\left(L P_{1}, L P_{2}\right)=\rho\left(L P_{1}^{\prime}, L P_{2}^{\prime}\right)=-0.866
$$

If we utilize the method defined by Mao et al. [12] to calculate the PLTS correlation coefficient between $L P_{1}$ and $L P_{2}$, then we obtain $\kappa\left(L P_{1}, L P_{2}\right)=0.8940$.

Moreover, the method proposed by Lin et al. [33] cannot be applied to calculate the correlation coefficient between $L P_{1}$ and $L P_{2}$ as given in this example. The reason is that this form of correlation coefficient given developed by Lin et al. [33] actually reflects the correlated relationship between two PLTS vectors rather than two PLTSs because all elements in each PLTS are simply aggregated a single value by the formula $\sum_{k=1}^{\# L P}\left(s^{(l)} p^{(l)}\right) / \sum_{k=1}^{\# L P} p^{(l)}$. Therefore, it is impossible to calculate the correlation coefficient between two values.

Following the results of example 1, the value of the PLTS Pearson correlation coefficient is negative using our proposed method, wherein it is positive with the method proposed in [12]. The reason is that the PLTS correlation coefficient defined in [12] is always positive. Thus, it can only describe the positive correlation but lose sight of the negative correlation situation. However, the value of the correlation coefficient given in this paper lies in $[-1,1]$, which is consistent with the feature of the classical correlation coefficient in statistics. Therefore, it can measure the positive correlation as well as the negative correlation situations, which overcomes the drawbacks of the current method. 
In some actual decision making processes, the weights of the attributes may be different. For the purpose of highlighting the importance of the attribute weights, we further present the weighted PLTS Pearson correlation coefficient:

Definition 14. Let $C=\left\{c_{1}, c_{2}, \cdots, c_{n}\right\}$ be a set of $n$ criteria with a weighting vector $w=\left(w_{1}, w_{2}, \cdots, w_{n}\right)^{T}$, where $w_{i} \in[0,1]$ and $\sum_{i=1}^{n} w_{i}=1$. Let $P_{1}=\left\{\left\langle c_{i}, L P_{1 i}\right\rangle \mid c_{i} \in C\right\}$ and $\left.P_{2}=\left\{<c_{i}, L P_{2 i}\right\rangle \mid c_{i} \in C\right\}$ be two different collections of PLTSs defined in LTS $S=\left\{s_{1}, s_{2}, \cdots, s_{7}\right\}$. Then, the weighted PLTS Pearson correlation coefficient can be defined as follows:

$$
\rho_{w}\left(P_{1}, P_{2}\right)=\sum_{i=1}^{n} w_{i} \rho\left(L P_{1 i}, L P_{2 i}\right)
$$

Theorem 2. The weighted PLTS Pearson correlation coefficient $\rho_{w}\left(P_{1}, P_{2}\right)$ has following important properties:

$$
\begin{aligned}
& \rho_{w}\left(P_{1}, P_{2}\right)=\rho_{w}\left(P_{2}, P_{1}\right) ; \\
& \text { if } P_{1}=P_{2}, \text { then } \rho_{w}\left(P_{1}, P_{2}\right)=1 ; \\
& \left|\rho_{w}\left(P_{1}, P_{2}\right)\right| \leq 1 .
\end{aligned}
$$

Proof. These theorems are analogous to theorem 1, and thus are omitted.

\section{A Pearson Correlation-Based TOPSIS Approach for MADM Problems}

The TOPSIS is one of the most efficient and popular approaches for handling MADM problems and has received continuous attention from scientists and scholars [18,32,34-36]. In this section, we put forward a correlation-based TOPSIS method to address uncertain MADM problems under a PLTS context.

Consider a MADM problem within PLTS situation: $X=\left\{x_{1}, x_{2}, \cdots, x_{m}\right\}$ is a finite set of alternatives, and $C=\left\{c_{1}, c_{2}, \cdots, c_{n}\right\}$ is a set of attributes with a weighting vector $w=\left(w_{1}, w_{2}, \cdots, w_{n}\right)^{T}$, where $w_{i} \in[0,1]$ and $\sum_{i=1}^{n} w_{i}=1$. The decision makers provide evaluation information by means of PLTS $L P_{i j}=\left\{L_{i j}^{(l)}\left(p_{i j}^{(l)}\right) \mid L_{i j}^{(l)} \in S, l=1,2, \cdots, \# L P_{i j}\right\}$ by using the LTS $S=\left\{s_{\alpha} \mid \alpha=0,1,2, \cdots, \tau\right\}$. The PLTS $L P_{i j}$ denotes the evaluation value over the alternatives $x_{i} \in X$ related to the attributes $c_{j} \in C$, where $L_{i j}^{(l)}$ is the $l$ th value of $L P_{i j}, p_{i j}^{(l)}$ is the probability of $L{ }_{i j}^{(l)}$, and $\# L P_{i j}$ is the number of linguistic terms in $L P_{i j}$. Accordingly, the PLTS decision matrix $R=\left[L P_{i j}\right]_{m \times n}$ can be formed as:

$$
R=\left[L P_{i j}\right]_{m \times n}=\left[\begin{array}{cccc}
L P_{11} & L P_{12} & \cdots & L P_{1 n} \\
L P_{21} & L P_{22} & \cdots & L P_{2 n} \\
\vdots & \vdots & \ddots & \vdots \\
L P_{m 1} & L P_{m 2} & \cdots & L P_{m n}
\end{array}\right]
$$

In order to facilitate anchoring judgment, we shall identify the PLTS positive ideal solution (PIS) as well as the PLTS negative ideal solution (NIS) for MADM problems. Generally, the larger the evaluative rating is, the greater the preference is for the benefit attribute and the less the preference is for the cost attribute.

Definition 15. Let $R=\left[L P_{i j}\right]_{m \times n}$ be a PLTS decision matrix. The PIS $P_{*}$ and NIS $P_{\#}$ is defined as follows:

$$
P_{*}=\left\{<c_{1}, L P_{* 1}>,<c_{2}, L P_{* 2}>, \cdots,<c_{n}, L P_{* n}>\right\} \text {. }
$$




$$
P_{\#}=\left\{<c_{1}, L P_{\# 1}>,<c_{2}, L P_{\# 2}>, \cdots,<c_{n}, L P_{\# n}>\right\} .
$$

Here, $L P_{* j}$ and $L P_{\# j}$ are defined as:

$$
\begin{gathered}
L P_{* j}= \begin{cases}\max _{\substack{m=1 \\
m}}^{m} L P_{i j}, & \text { benefit attribute } c_{j} \\
\min _{i=1} L P_{i j}, & \text { cost attribute } c_{j}\end{cases} \\
L P_{\# j}=\left\{\begin{array}{ll}
\min _{i=1}^{m} L P_{i j}, & \text { benefit attribute } c_{j} \\
\max _{i=1}^{m} L P_{i j}, & \text { cost attribute } c_{j}
\end{array} .\right.
\end{gathered}
$$

In general, the larger $\rho_{w}\left(P_{i}, P_{*}\right)$ is, the better $x_{i}$ is. That is to say, the stronger the positive correlation between $P_{i}$ and $P_{*}$ is, the better $x_{i}$ is. On the contrary, the smaller $\rho_{w}\left(P_{i}, P_{\#}\right)$ is, the better $x_{i}$ is, and the weaker the negative correlation between $P_{i}$ and $P_{*}$ is, the better $x_{i}$ is. However, the $P_{i}$ that is the strongest positive correlation with $P_{*}$ does not accord with the one that is the weakest negative correlation with $P_{\#}$. So we need a closeness coefficient to identify the degree to which the PLTSs $P_{i}$ is highly correlated to $P_{*}$ and far from $P_{\#}$ simultaneously. However, the existing TOPSIS method concerning PLTS MADM mostly utilize the distance and similarity measures to define the relative closeness, and these information measures are all positive. Therefore, we cannot apply the PLTS Pearson correlation coefficient with negative part into existing TOPSIS method to make decision directly as distance and similarity measures. To address this problem, we define a weighted PLTS Pearson correlation-based closeness index $\mathrm{CC}_{1}{ }^{w}\left(P_{i}\right)$ :

$$
\mathrm{CC}_{1}^{w}\left(P_{i}\right)=\frac{1+\rho_{w}\left(P_{i}, P_{*}\right)}{1+\max \left\{\rho_{w}\left(P_{i}, P_{*}\right)\right\}}-\frac{1+\rho_{w}\left(P_{i}, P_{\#}\right)}{1+\min \left\{\rho_{w}\left(P_{i}, P_{\#}\right)\right\}} .
$$

It is easy to find that $C C_{1}{ }^{w}\left(P_{i}\right) \leq 0$, and the bigger $C C_{1}{ }^{w}\left(P_{i}\right)$ is, the better $x_{i}$ will be. Particularly, if an alternative $x_{i}$ satisfies $1+\rho_{w}\left(P_{i}, P_{*}\right)=1+\max \left\{\rho_{w}\left(P_{i}, P_{*}\right)\right\}$ as well as $1+\rho_{w}\left(P_{i}, P_{\#}\right)=1+$ $\min \left\{\rho_{w}\left(P_{i}, P_{\#}\right)\right\}$, then $C C_{1}{ }^{w}\left(P_{i}\right)=0$, which means that the alternative $x_{i}$ is the most suitable candidate as it has the strongest liner correlation to the PIS as well as the weakest liner correlation to the NIS.

Based on the defined Pearson correlation-based closeness coefficient, we then propose a correlation-based TOPSIS model for handling MADM problems with the PLTS context. The main steps can be summarized as follows:

Step 1. Establish the PLTS decision matrix $R=\left[L P_{i j}\right]_{m \times n}$ according to the PLTS evaluation information provided by decision makers and then get the normalized PLTS decision matrix $R^{\prime}=\left[L P_{i j}^{\prime}\right]_{m \times n}$

Step 2. Calculate the PIS $P_{*}$ and the NIS $P_{\#}$.

Step 3. Calculate the weighted PLTS Pearson correlation coefficients $\rho_{w}\left(P_{i}, P_{*}\right)$ and $\rho_{w}\left(P_{i}, P_{\#}\right)$ for each $x_{i} \in X$.

Step 4. Utilize the Equation (15) to calculate the weighted PLTS Pearson correlation-based closeness coefficient $C C_{1}{ }^{w}\left(P_{i}\right)$ for each $x_{i} \in X$.

Step 5. Sort the alternatives in accordance with the descending order of the $C C_{1}{ }^{w}\left(P_{i}\right)$.

Step 6. End.

\section{An Illustrative Example}

A numerical example concerning hospital assessment [2] is used to verify the practicability and effectiveness of the developed method. With the increasing shortage of medical resources, how to optimize resource allocation and improve the efficiency of resource input and output has become a thorny problem in China. Recently, some domestic hospitals have begun to optimize the allocation 
of resources and improve the input and output efficiency of resources. The following three main attributes with the weigh vector $w=(0.2,0.1,0.7)^{T}$ are considered during evaluation process: (1) the environment factor of health and medical service $\left(c_{1}\right)$; $(2)$ treatment optimization and personalized diagnosis $\left(c_{2}\right)$; and (3) social resource allocation optimization under the pattern of wisdom health and medical services $\left(c_{3}\right)$. There are four hospitals need to be assessed, i.e., the Chinese PLA General Hospital $\left(x_{1}\right)$, the Huashan Hospital of Fudan University $\left(x_{2}\right)$, the Union Medical College Hospital $\left(x_{3}\right)$ and the West China Hospital of Sichuan University $x_{4}$. The invited experts from the evaluation team utilize the LTS $S=\left\{s_{\alpha} \mid \alpha=0,1,2, \cdots, 6\right\}$ to evaluate the hospitals $x_{i}(i=1,2, \cdots, 4)$. The experts' PLTS evaluations are shown in Table 1.

Table 1. The probabilistic linguistic term set (PLTS) decision matrix.

\begin{tabular}{cccc}
\hline & $c_{1}$ & $c_{2}$ & $c_{3}$ \\
\hline$x_{1}$ & $\left\{s_{3}(0.4), s_{4}(0.6)\right\}$ & $\left\{s_{5}(1)\right\}$ & $\left\{s_{2}(0.2), s_{3}(0.8)\right\}$ \\
$x_{2}$ & $\left\{s_{5}(0.3), s_{6}(0.7)\right\}$ & $\left\{s_{3}(0.8)\right\}$ & $\left\{s_{4}(0.2), s_{5}(0.4), s_{6}(0.4)\right\}$ \\
$x_{3}$ & $\left\{s_{4}(1)\right\}$ & $\left\{s_{4}(0.5), s_{5}(0.5)\right\}$ & $\left\{s_{5}(0.6), s_{6}(0.4)\right\}$ \\
$x_{4}$ & $\left\{s_{5}(0.4), s_{6}(0.4)\right\}$ & $\left\{s_{1}(0.4), s_{2}(0.1), s_{3}(0.2), s_{4}(0.3)\right\}$ & $\left\{s_{4}(0.9)\right\}$ \\
\hline
\end{tabular}

The detailed steps involving the developed method that are executed to determine the best alternative(s) are illustrated as follows.

Step 1. Normalize the PLTS decision matrix using definitions 2, 3, and 9, and the normalized PLTS decision matrix $R^{\prime}=\left[L P_{i j}^{\prime}\right]_{4 \times 3}$ is shown in Table 2 .

Table 2. The normalized PLTS decision matrix.

\begin{tabular}{cccc}
\hline & $c_{1}$ & $c_{2}$ & $c_{3}$ \\
\hline$x_{1}$ & $\left\{s_{4}(0.6), s_{3}(0.4)\right\}$ & $\left\{s_{5}(1), s_{5}(0), s_{5}(0), s_{5}(0)\right\}$ & $\left\{s_{3}(0.8), s_{2}(0.2), s_{2}(0)\right\}$ \\
$x_{2}$ & $\left\{s_{6}(0.7), s_{5}(0.3)\right\}$ & $\left\{s_{3}(1), s_{3}(0), s_{3}(0), s_{3}(0)\right\}$ & $\left\{s_{6}(0.4), s_{5}(0.4), s_{4}(0.2)\right\}$ \\
$x_{3}$ & $\left\{s_{4}(1), s_{4}(0)\right\}$ & $\left\{s_{5}(0.5), s_{4}(0.5), s_{4}(0), s_{4}(0)\right\}$ & $\left\{s_{6}(0.4), s_{5}(0.6), s_{5}(0)\right\}$ \\
$x_{4}$ & $\left\{s_{6}(0.5), s_{5}(0.5)\right\}$ & $\left\{s_{4}(0.3), s_{3}(0.2), s_{2}(0.1), s_{1}(0.4)\right\}$ & $\left\{s_{4}(1), s_{4}(0), s_{4}(0)\right\}$ \\
\hline
\end{tabular}

Step 2. Determine the PIS $P_{*}$ and NIS $P_{\#}$ by using Equation (11) to (14):

$$
\begin{gathered}
p_{*}=\left(\begin{array}{l}
<c_{1},\left\{s_{6}(0.7), s_{5}(0.3)\right\}>,<c_{2},\left\{s_{5}(1), s_{5}(0), s_{5}(0), s_{5}(0)\right\}>, \\
<c_{3},\left\{s_{6}(0.4), s_{5}(0.6), s_{5}(0)\right\}>
\end{array}\right), \\
p_{\#}=\left(\begin{array}{l}
<c_{1},\left\{s_{4}(0.6), s_{3}(0.4)\right\}>,<c_{2},\left\{s_{4}(0.3), s_{3}(0.2), s_{2}(0.1), s_{1}(0.4)\right\}>, \\
<c_{3},\left\{s_{3}(0.8), s_{2}(0.2), s_{2}(0)\right\}>
\end{array}\right) .
\end{gathered}
$$

Step 3. Calculate the weighted PLTS Pearson correlation coefficients $\rho_{w}\left(P_{i}, P_{*}\right)$ and $\rho_{w}\left(P_{i}, P_{\#}\right)$ for each $x_{i} \in X(i=1,2, \cdots, 4)$ according to the definition 14 :

$$
\begin{aligned}
& \rho_{w}\left(P_{1}, P_{*}\right)=0.6292, \rho_{w}\left(P_{1}, P_{\#}\right)=0.9926 ; \\
& \rho_{w}\left(P_{2}, P_{*}\right)=0.9355, \rho_{w}\left(P_{2}, P_{\#}\right)=0.8505 ; \\
& \rho_{w}\left(P_{3}, P_{*}\right)=0.9697, \rho_{w}\left(P_{3}, P_{\#}\right)=0.6172 ; \\
& \rho_{w}\left(P_{4}, P_{*}\right)=0.5217, \rho_{w}\left(P_{4}, P_{\#}\right)=0.9915 .
\end{aligned}
$$

Step 4. Utilize Equation (15) to compute the closeness index for each $x_{i} \in X(i=1,2, \cdots, 4)$ :

$$
\mathrm{CC}_{1}{ }^{w}\left(P_{1}\right)=-0.4050 C C_{1}{ }^{w}\left(P_{2}\right)=-0.1616, C_{1}{ }^{w}\left(P_{3}\right)=0, C_{1}{ }^{w}\left(P_{4}\right)=-0.4589 .
$$


Step 5. Rank the alternative $x_{i} \in X$ according to $C_{1}{ }^{w}\left(P_{i}\right)(i=1,2, \cdots, 4)$ :

$$
x_{3}>x_{2}>x_{1}>x_{4}
$$

Therefore, the best candidate is the Union Medical College Hospital $\left(x_{3}\right)$.

Step 6. End.

\section{Comparative Analysis}

The practicability and superiority of the proposed methodology are further verified in this section through the comparison with the current approaches. First, we choose the distance-based TOPSIS framework proposed in [1] to rank the alternatives. Then, we explore the effects of different PLTS correlation coefficients on the calculation results and ranking orders. Furthermore, we consider the application of the TOPSIS method proposed by Sun et al. [32]. Finally, we compare our method with the correlation-based TOPSIS framework proposed by Chen [30].

6.1. Comparison with Distance-Based TOPSIS Method Proposed by Pang (Pang et al., Inf. Sci. 2016, 369, 128-143)

The distance-based TOPSIS method for MADM problems with the PLTS information developed by Pang et al. [1] is similar to the method proposed in this paper. However, the former focuses on the degree of the distances between the candidates and the PIS as well as NIS, and our method considers the degree of the linear correlation between the potential candidates and the PIS as well as NIS. The procedures of the distance-based TOPSIS model introduced in [1] are shown as follows.

Step 1. Normalize the PLTS decision information.

Step 2. Identify the PIS $L(p)^{*}$ as well as NIS $L(p)^{\#}$ :

$$
\begin{gathered}
L(p)^{*}=\left(\left\{s_{4.2}, s_{2.5}\right\},\left\{s_{5}, s_{2}, s_{0.4}, s_{0.2}\right\},\left\{s_{4}, s_{2.4}, s_{0.8}\right\}\right), \\
L(p)^{\#}=\left(\left\{s_{2.4}, s_{0}\right\},\left\{s_{1.2}, s_{0}, s_{0}, s_{0}\right\},\left\{s_{2.4}, s_{0}, s_{0}\right\}\right)
\end{gathered}
$$

where $L(p)^{*}=\left(\widetilde{S}_{1}+, \widetilde{S}_{2}+, \ldots, \widetilde{S}_{n}^{+}\right), \widetilde{S}_{j}^{+}=\left\{S_{\left(\widetilde{L}_{j}^{(k)} \cdot p_{j}^{(k)}\right)}+k=1,2, \cdots, \eta\right\}$, and $\left(\widetilde{L}_{j}^{(k)} \cdot p_{j}^{(k)}\right)^{+}=$ $\max _{i}\left\{\widetilde{L}_{j}^{(k)} \cdot p_{j}^{(k)}\right\}(i=1,2, \cdots, m ; j=1,2, \cdots, n)$.

Similarity, $L(p)^{\#}=\left(\widetilde{S}_{1}{ }^{-}, \widetilde{S}_{2}^{-}, \cdots, \widetilde{S}_{n}{ }^{-}\right), \widetilde{S}_{j}^{-}=\left\{S_{\left(L_{j}^{(k)} \cdot p_{j}^{(k)}\right)}{ }^{-} \mid k=1,2, \cdots, \eta\right\}$, and $\left(\widetilde{L}_{j}^{(k)} \cdot p_{j}^{(k)}\right)^{-}=$ $\min _{i}\left\{\widetilde{L}_{j}^{(k)} \cdot p_{j}^{(k)}\right\}(i=1,2, \cdots, m ; j=1,2, \cdots, n)$

Step 3. Utilize Equations (16) and (17) to compute the deviation degrees between each alternative and the PIS $L(p)^{*}$ and NIS $L(p)^{\#}$, respectively:

$$
\begin{gathered}
d\left(x_{1}, L(p)^{*}\right)=1.5009, d\left(x_{2}, L(p)^{*}\right)=0.9511, d\left(x_{3}, L(p)^{*}\right)=0.9992, \\
d\left(x_{4}, L(p)^{*}\right)=1.3946, d\left(x_{1}, L(p)^{\#}\right)=0.5214, d\left(x_{2}, L(p)^{\#}\right)=1.2919 \\
d\left(x_{3}, L(p)^{\#}\right)=1.3453, d\left(x_{4}, L(p)^{\#}\right)=1.0476
\end{gathered}
$$

where

$$
\begin{aligned}
& d\left(x_{i}, L(p)^{*}\right)=\sum_{j=1}^{n} w_{j} \sqrt{\frac{1}{\# L P_{i j}} \sum_{l=1}^{\# L P_{i j}}\left(p_{i j}^{(l)} s_{i j}^{(l)}-\left(p_{j}^{(l)} s_{j}^{(l)}\right)^{*}\right)^{2}} \\
& d\left(x_{i}, L(p)^{\#)}=\sum_{j=1}^{n} w_{j} \sqrt{\frac{1}{\# L P_{i j}} \sum_{l=1}^{\# L P_{i j}}\left(p_{i j}^{(l)} s_{i j}^{(l)}-\left(p_{j}^{(l)} s_{j}^{(l)}\right)^{\#}\right)^{2}}\right.
\end{aligned}
$$


Step 4. Derive the closeness index $C I\left(x_{i}\right)$ of each alternative $x_{i} \in X(i=1,2, \cdots, 4)$ :

$$
C I\left(x_{1}\right)=-1.1905, C I\left(x_{2}\right)=-0.0397, C I\left(x_{3}\right)=-0.0506, C I\left(x_{4}\right)=-0.6875
$$

where

$$
C I\left(x_{i}\right)=\frac{d\left(x_{i}, L(p)^{\#}\right)}{d_{\max }\left(x_{i}, L(p)^{\#}\right)}-\frac{d\left(x_{i}, L(p)^{*}\right)}{d_{\min }\left(x_{i}, L(p)^{*}\right)}
$$

Step 5. Rank the alternative $x_{i} \in X$ in accordance with $C I\left(x_{i}\right)(i=1,2, \cdots, 4)$ :

$$
x_{2}>x_{3}>x_{4}>x_{1} .
$$

Therefore, the best alternative is $x_{2}$.

6.2. Comparison with the PLTS Correlation Coefficient Proposed by Lin (Lin et al., Int. J. Intell. Syst. 2018, 33, 2402-2424)

The computational process and results utilizing the weighted PLTS correlation coefficient defined in [33] are illustrated as follows:

Step 1. Standardize the PLTS decision matrix.

Step 2. Identify the PIS $L(p)^{+}$as well as NIS $L(p)^{-}$:

$$
\begin{gathered}
L(p)^{+}=\left(<c_{1},\left\{s_{5}(0.3), s_{6}(0.7)\right\}>,<c_{2},\left\{s_{5}(1)\right\}>,<c_{3},\left\{s_{5}(0.6), s_{6}(0.4)\right\}>\right), \\
L(p)^{-}=\left(\begin{array}{l}
<c_{1},\left\{s_{3}(0.4), s_{4}(0.6)\right\}>,<c_{2},\left\{s_{1}(0.4), s_{2}(0.1), s_{3}(0.2), s_{4}(0.3)\right\}>, \\
<c_{3},\left\{s_{2}(0.2), s_{3}(0.8)\right\}>
\end{array}\right) .
\end{gathered}
$$

Step 3. Calculate the weighted PLTS correlation coefficients $\xi_{w}\left(L\left(p_{i}\right), L(p)^{+}\right)$and $\xi_{w}\left(L\left(p_{i}\right), L(p)^{-}\right)$ for each $x_{i} \in X(i=1,2, \cdots, 4)$ :

$$
\begin{aligned}
& \xi_{w}\left(L\left(p_{1}\right), L(p)^{+}\right)=0.9580, \xi_{w}\left(L\left(p_{1}\right), L(p)^{-}\right)=0.9713 ; \\
& \xi_{w}\left(L\left(p_{2}\right), L(p)^{+}\right)=0.9965, \xi_{w}\left(L\left(p_{2}\right), L(p)^{-}\right)=0.9900 ; \\
& \xi_{w}\left(L\left(p_{3}\right), L(p)^{+}\right)=0.9849, \xi_{w}\left(L\left(p_{3}\right), L(p)^{-}\right)=0.9596 ; \\
& \xi_{w}\left(L\left(p_{4}\right), L(p)^{+}\right)=0.9886, \xi_{w}\left(L\left(p_{4}\right), L(p)^{-}\right)=0.9981 .
\end{aligned}
$$

Step 4. Utilize Equation (15) to compute the weighted PLTS Pearson correlation-based closeness coefficient for each $x_{i} \in X(i=1,2, \cdots, 4)$ :

$$
C C_{1}{ }^{w}\left(P_{1}\right)=-0.0253, C C_{1}{ }^{w}\left(P_{2}\right)=-0.0155, C C_{1}^{w}\left(P_{3}\right)=-0.0058, C_{1}{ }^{w}\left(P_{4}\right)=-0.0236 .
$$

Step 5. Rank the alternative $x_{i} \in X$ according to $C C_{1}{ }^{w}\left(P_{i}\right)(i=1,2, \cdots, 4)$ :

$$
x_{3}>x_{2}>x_{4}>x_{1} .
$$

Therefore, the best candidate is also the Union Medical College Hospital $\left(x_{3}\right)$. 
6.3. Comparison with the Correlation-Based Closeness Proposed by Sun (Sun et al., Appl. Soft Comput. 2018, $68,249-267)$

To expand the application of the classic TOPSIS, instead of using a distance measure to calculate the closeness coefficient, Sun et al. [32] proposed a new TOPSIS method and utilized the correlation coefficient to construct four types of relative closeness:

$$
\begin{gathered}
\eta_{i}=\frac{\lambda \varsigma_{i}^{+}}{(1-\lambda) \varsigma_{i}^{+}+\lambda \varsigma_{i}^{-}}, \quad i=1,2, \cdots, m \\
\delta_{i}=\frac{(1-v) \mu_{i}^{-}}{v \mu_{i}^{+}+(1-v) \mu_{i}^{-}}, \quad i=1,2, \cdots, m \\
\vartheta_{i}=1-\left(v \mu_{i}^{+}+(1-v) \varsigma_{i}^{-}\right), \quad i=1,2, \cdots, m \\
\xi_{i}=\lambda \varsigma_{i}^{+}+(1-\lambda) \mu_{i}^{-}, \quad i=1,2, \cdots, m
\end{gathered}
$$

where

$$
\begin{aligned}
\varsigma_{i}^{+} & =\frac{\rho_{w}\left(P_{i}, P_{*}\right)-\min \left\{\rho_{w}\left(P_{i}, P_{*}\right)\right\}}{\max \left\{\rho_{w}\left(P_{i}, P_{*}\right)\right\}-\min \left\{\rho_{w}\left(P_{i}, P_{*}\right)\right\}}, \quad i=1,2, \cdots, m \\
\varsigma_{i}^{-} & =\frac{\rho_{w}\left(P_{i}, P_{\#}\right)-\min \left\{\rho_{w}\left(P_{i}, P_{\#}\right)\right\}}{\max \left\{\rho_{w}\left(P_{i}, P_{\#}\right)\right\}-\min \left\{\rho_{w}\left(P_{i}, P_{\#}\right)\right\}}, i=1,2, \cdots, m \\
\mu_{i}^{+} & =\frac{\max \left\{\rho_{w}\left(P_{i}, P_{*}\right)\right\}-\rho_{w}\left(P_{i}, P_{*}\right)}{\max \left\{\rho_{w}\left(P_{i}, P_{*}\right)\right\}-\min \left\{\rho_{w}\left(P_{i}, P_{*}\right)\right\}}, i=1,2, \cdots, m \\
\mu_{i}^{+} & =\frac{\max \left\{\rho_{w}\left(P_{i}, P_{\#}\right)\right\}-\rho_{w}\left(P_{i}, P_{\#}\right)}{\max \left\{\rho_{w}\left(P_{i}, P_{\#}\right)\right\}-\min \left\{\rho_{w}\left(P_{i}, P_{\#}\right)\right\}}, i=1,2, \cdots, m,
\end{aligned}
$$

and the parameters $\lambda$ and $v$ lie in the interval $[0,1]$.

The results obtained by the above method (let $\lambda=v=0.5$ ) are listed in Table 3 .

Table 3. The results rendered by the method in [32].

\begin{tabular}{cccccc}
\hline & $x_{1}$ & $x_{2}$ & $x_{3}$ & $x_{4}$ & Rankings \\
\hline$\eta_{i}$ & 0.1935 & 0.5977 & 1 & 0 & $x_{3}>x_{2}>x_{1}>x_{4}$ \\
$\delta_{i}$ & 0 & 0.8322 & 1 & 0.0029 & $x_{3}>x_{2}>x_{4}>x_{1}$ \\
$\xi_{i}=\vartheta_{i}$ & 0.1200 & 0.6511 & 1 & 0.0015 & $x_{3}>x_{2}>x_{1}>x_{4}$ \\
\hline
\end{tabular}

We observe from Table 3 that the best candidate calculated from the four types of relative closeness is, again, the Union Medical College Hospital $\left(x_{3}\right)$.

6.4. Comparison with the Correlation-Based TOPSIS Framework Proposed by Chen (Chen, Int. J. Intell. Syst. 2019, 34, 114-151)

Chen [30] proposed a correlation-based, rather than a distance-based, closeness coefficient to select the best alternatives in interval-valued Pythagorean fuzzy MADM problems:

$$
C_{2}{ }^{w}\left(P_{i}\right)=\frac{1+\xi_{w}\left(L\left(p_{i}\right), L(p)^{+}\right)}{2+\xi_{w}\left(L\left(p_{i}\right), L(p)^{+}\right)+\xi_{w}\left(L\left(p_{i}\right), L(p)^{-}\right)}
$$

Clearly, the alternative(s) with the largest value of $\mathrm{CC}_{2}{ }^{w}\left(P_{i}\right)$ can be selected as the best alternative(s). Whereas, we use Equation (27) to compute the closeness coefficient for alternative $x_{i}$, then we obtain:

$$
C_{2}{ }^{w}\left(p_{1}\right)=0.4983 ; C C_{2}{ }^{w}\left(p_{2}\right)=0.5008 ; C C_{2}{ }^{w}\left(p_{3}\right)=0.5032 ; C C_{2}{ }^{w}\left(p_{4}\right)=0.4988 ;
$$


thus, according to the values of $C C_{2}{ }^{w}\left(P_{i}\right)(i=1,2, \cdots, 4)$, we can find the ordering:

$$
x_{3}>x_{2}>x_{4}>x_{1} .
$$

Therefore, the best candidate is also the Union Medical College Hospital $\left(x_{3}\right)$.

We note that different rankings of the potential alternatives as well as the best alternative are produced by different decision methods. The presented method in this paper and the methods introduced in $[30,32,33]$ obtain the same optimal alternative, i.e., the Union Medical College Hospital $\left(x_{3}\right)$, which demonstrates the validity and capability of our proposed correlation-based TOPSIS formula. The best choice obtained by the distance-based TOPSIS method introduced in [1] is the Huashan Hospital of Fudan University $\left(x_{2}\right)$.

The main reasons can be summed up in two aspects. On the one hand, the methods of dealing with the original PLTS decision information may result in a different PIS as well as NIS, and these play a great role in the final decision. The developed new ranking rules in this paper for normalizing the original PLTS decision information is beneficial to overcome the shortcomings of the existing normalization technique proposed by Pang et al. [1]. On the other hand, the different information measures used in the TOPSIS methods may affect the decision results. As we mentioned above, there are defects in the current PLTS correlation coefficient proposed by Lin et al. [33], which often lead to biased results. In particular, the PLTS correlation coefficient proposed by Lin et al. [33] does not have the normalization process, and it is only a mean type correlation coefficient.

While the correlation coefficient defined in this article lies in the interval $[-1,1]$ conforming to the statistics, which is superior in discrimination, and makes full use of the decision information by standardizing and normalizing the original PLTS decision matrix information as it focuses on the linguistic variables and the corresponding probabilistic information in each PLTS. Thus, it maintains the decision information as integrated and as authentic as possible. Furthermore, the distance-based method proposed in Pang et al. [1] cannot deal with the information measures with negative values directly, while the presented approach in this paper successfully solves the negative information measures so as to broaden the application scope of TOPSIS model.

\section{Conclusions}

The PLTS is a very popular tool as it can not only express the preference of decision makers for certain things more comprehensively, but also quantify the degree of preference. To enrich the theory and application of PLTSs, this paper proposed a new correlation coefficient for solving PLTS MADM problems. The presented Pearson correlation coefficient for PTLSs, combining the new concept of mean, variance, and covariance, effectively eliminated the flaws in the existing methods. Moreover, a novel comprehensive closeness coefficient was presented to depict a certain degree of the correlations with the PLTS positive- as well as negative-ideal solutions. A PLTS correlation-based TOPSIS framework was further established for solving MADM problems within the PLTS contexts. The superiority and validity of the developed methodology were verified by a numerical example and corresponding comparative analysis.

The advantages of our study are summarized as follows: (1) The proposed correlation coefficient lies in the interval $[-1,1]$ conforming to the statistics. This coefficient is superior in discrimination, and is more convincing than the existing correlation coefficients by considering all elements in each PLTS. (2) Compared with existing TOPSIS methods based on distance and similarity measures, the proposed correlation-based TOPSIS method uses the correlation coefficient to measure the proximity between each alternative and ideal solution. It is innovative way to make the decision under a PLTS context. (3) The proposed method is effective for handling the negative correlation between the alternatives and ideal solutions, while the existing TOPSIS method cannot deal with this situation under a PLTS context.

However, our study still has some limitations as follows: (1) Under increasingly complex decision-making environments, it is insufficient to only consider a single decision matrix provided 
by decision makers. (2) As the calculated process of the presented correlation coefficient is more complicated than some existing measures, the time complexity of our method is higher. (3) The proposed method is given under the condition that the attribute weights are known, and we did not discuss the conditions where the attribute weight is unknown or partly known.

Regarding future works, we intend to offer further applications of the correlation-based TOPSIS approach by utilizing additional fuzzy techniques, e.g., single valued neutrosophic sets and spherical fuzzy sets. Moreover, consensus process is an important branch of group decision-making problems [37-39]. It will be interesting to combine the consensus model with the correlation-based TOPSIS model to address group decision-making problems [40-45]. Other empirical extensions of this approach will also be considered in future studies.

Author Contributions: Methodology, J.C.; Writing-original draft, D.L.; Writing-review \& editing, S.Z. All authors contributed equally to this work. All authors have read and agreed to the published version of the manuscript.

Funding: This paper was supported by Major Humanities and Social Sciences Research Projects in Zhejiang Universities (No. 2018QN058), China Postdoctoral Science Foundation (No. 2019M651403), National Social Science Found of China (no. 16BTJ026), Zhejiang Province Natural Science Foundation (No. LY18G010007), Ningbo Natural Science Foundation (No. 2019A610037) and First Class Discipline of Zhejiang-A (Zhejiang Gongshang University - Statistics).

Acknowledgments: The authors are very grateful to the anonymous referees for their valuable comments and suggestions that have helped us to improve considerably the quality of this paper.

Conflicts of Interest: The authors declare no conflict of interest.

\section{References}

1. Pang, Q.; Wang, H.; Xu, Z.S. Probabilistic linguistic term sets in multi-attribute group decision making. Inf. Sci. 2016, 369, 128-143. [CrossRef]

2. Gou, X.J.; Xu, Z.S. Novel basic operational laws for linguistic terms, hesitant fuzzy linguistic term sets and probabilistic linguistic term sets. Inf. Sci. 2016, 372, 407-427. [CrossRef]

3. Lin, M.W.; Xu, Z.S. Probabilistic Linguistic Distance Measures and Their Applications in Multi-Criteria Group Decision Making; Soft Computing Applications for Group Decision-making and Consensus Modeling; Springer International Publishing: Berlin/Heidelberg, Germany, 2018.

4. Wu, X.L.; Liao, H.C.; Xu, Z.S.; Hafezalkotob, A. Probabilistic linguistic MULTIMOORA: A multicriteria decision making method based on the probabilistic linguistic expectation function and the improved Borda rule. IEEE Trans. Fuzzy Syst. 2018, 26, 3688-3702. [CrossRef]

5. Bai, C.Z.; Zhang, R.; Qian, L.X.; Wu, Y.N. Comparisons of probabilistic linguistic term sets for multi-criteria decision making. Knowl.-Based Syst. 2017, 119, 284-291. [CrossRef]

6. Liu, P.D.; Li, Y. The PROMTHEE II method based on probabilistic linguistic information and their application to decision making. Information 2018, 29, 303-320. [CrossRef]

7. Lin, H.B.; Jiang, L.; Xu, Z.S. Entropy measures of probabilistic linguistic term sets. Int. J. Comput. Intell. Syst. 2018, 11, 45-87.

8. Zhang, Y.X.; Xu, Z.S.; Liao, H.C. Water security evaluation based on the TODIM method with probabilistic linguistic term sets. Soft Comput. 2019, 23, 6215-6230. [CrossRef]

9. Liu, P.D.; You, X.L. Probabilistic linguistic TODIM approach for multiple attribute decision-making. Granul. Comput. 2017, 2, 333-342. [CrossRef]

10. Wu, X.L.; Liao, H.C. An approach to quality function deployment based on probabilistic linguistic term sets and ORESTE method for multi-expert multi-criteria decision making. Inf. Fusion 2018, 43, 13-26. [CrossRef]

11. Lin, M.W.; Chen, Z.Y.; Liao, H.C.; Xu, Z.S. ELECTRE II method to deal with probabilistic linguistic term sets and its application to edge computing. Nonlinear Dyn. 2019, 96, 2125-2143. [CrossRef]

12. Mao, X.B.; Wu, M.; Shang, N. The multi-attribute group decision making model based on probabilistic linguistic correlation coefficient. J. Jiangxi Norm. Univ. (Nat. Sci. Ed.) 2018, 42, 267-274.

13. Liu, P.D.; Li, Y. A Novel Decision-Making Method Based on Probabilistic Linguistic Information. Cogn. Comput. 2019, 11, 735-747. [CrossRef] 
14. Zhang, X.L.; Xing, X.M. Probabilistic Linguistic VIKOR Method to Evaluate Green Supply Chain Initiatives. Sustainability 2017, 9, 1231. [CrossRef]

15. Wang, X.K.; Wang, J.Q.; Zhang, H.Y. Distance-based multicriteria group decision-making approach with probabilistic linguistic term sets. Expert Syst. 2019, 36, e12352. [CrossRef]

16. Zhang, X.F.; Gou, X.J.; Xu, Z.S.; Liao, H.C. A projection method for multiple attribute group decision making with probabilistic linguistic term sets. Int. J. Mach. Learn. Cybern. 2019, 10, 2515-2528. [CrossRef]

17. Xian, S.D.; Chai, J.H.; Yin, Y.B. A visual comparison method and similarity measure for probabilistic linguistic term sets and their applications in multi-criteria decision making. Int. J. Fuzzy Syst. 2019, 21, 1154-1169. [CrossRef]

18. Lu, J.P.; Wei, C.; Wu, J.; Wei, G.W. TOPSIS method for probabilistic linguistic MAGDM with entropy weight and its application to supplier selection of new agricultural machinery products. Entropy 2019, 21, 953. [CrossRef]

19. Rodgers, J.L.; Nicewander, W.A. Thirteen ways to look at the correlation coefficient. Am. Stat. 1988, 42, 59-66. [CrossRef]

20. Zeng, S.Z.; Luo, D.D.; Zhang, C.H.; Li, X.S. A correlation-based TOPSIS method for multiple attribute decision making with single-valued neutrosophic information. Int. J. Inf. Technol. Decis. Mak. 2020. [CrossRef]

21. Huang, H.L.; Guo, Y.T. An improved correlation coefficient of intuitionistic fuzzy sets. J. Intell. Syst. 2019, 28, 231-243. [CrossRef]

22. Garg, H.; Rani, D. A robust correlation coefficient measure of complex intuitionistic fuzzy sets and their applications in decision-making. Appl. Intell. 2019, 49, 496-512. [CrossRef]

23. Su, G.D.; Guan, X.; Yi, X.; Zhou, Z. Improvements on Correlation Coefficients of Hesitant Fuzzy Sets and Their Applications. Cogn. Comput. 2019, 11, 529-544.

24. Liao, H.C.; Xu, Z.S.; Zeng, X.J. Novel correlation coefficients between hesitant fuzzy sets and their application in decision making. Knowl.-Based Syst. 2015, 82, 115-127. [CrossRef]

25. Zhang, R.C.; Li, Z.M.; Liao, H.C. Multiple-attribute decision-making method based on the correlation coefficient between dual hesitant fuzzy linguistic term sets. Knowl. -Based Syst. 2018, 159, 186-192. [CrossRef]

26. Song, C.Y.; Xu, Z.S.; Zhao, H. New Correlation Coefficients Between Probabilistic Hesitant Fuzzy Sets and Their Applications in Cluster Analysis. Int. J. Fuzzy Syst. 2019, 21, 355-368. [CrossRef]

27. Şahin, R.; Liu, P.D. Correlation coefficient of single-valued neutrosophic hesitant fuzzy sets and its applications in decision making. Neural Comput. Appl. 2017, 28, 1387-1395. [CrossRef]

28. Zeng, S.Z.; Peng, X.M.; Baležentis, T.; Streimikiene, D. Prioritization of low-carbon suppliers based on Pythagorean fuzzy group decision making with self-confidence level. Economic Research-Ekonomska Istraživanja 2019, 32, 1073-1087. [CrossRef]

29. Zeng, S.Z.; Su, W.H.; Zhang, C.H. Intuitionistic fuzzy generalized probabilistic ordered weighted averaging operator and its application to group decision making. Technol. Econ. Dev. Econ. 2016, 22, 177-193. [CrossRef]

30. Chen, T.Y. Multiple criteria decision analysis under complex uncertainty: A Pearson-like correlation-based Pythagorean fuzzy compromise approach. Int. J. Intell. Syst. 2019, 34, 114-151. [CrossRef]

31. Jin, Y.; Wu, H.C.; Sun, D.C.; Zeng, S.Z.; Luo, D.D.; Peng, B. A multi-attribute Pearson's picture fuzzy correlation-based decision-making method. Mathematics 2019, 7, 999. [CrossRef]

32. Sun, G.D.; Guan, X.; Yi, X.; Zhou, Z. An innovative TOPSIS approach based on hesitant fuzzy correlation coefficient and its applications. Appl. Soft Comput. 2018, 68, 249-267. [CrossRef]

33. Lin, M.W.; Wang, H.B.; Xu, Z.S. Clustering algorithms based on correlation coefficients for probabilistic linguistic term sets. Int. J. Intell. Syst. 2018, 33, 2402-2424. [CrossRef]

34. Zeng, S.Z.; Chen, S.M.; Fan, K.Y. Interval-valued intuitionistic fuzzy multiple attribute decision making based on nonlinear programming methodology and TOPSIS method. Inf. Sci. 2020, 506, 424-442. [CrossRef]

35. Zeng, S.Z.; Xiao, Y. A method based on TOPSIS and distance measures for hesitant fuzzy multiple attribute decision making. Technol. Econ. Dev. Econ. 2018, 24, 969-983. [CrossRef]

36. Zeng, S.Z.; Chen, J.P.; Li, X.S. A hybrid method for Pythagorean fuzzy multiple-criteria decision making. Int. J. Inf. Technol. Decis. Mak. 2016, 15, 403-422. [CrossRef]

37. Cabrerizo, F.J.; Urena, R.; Pedrycz, W.; Herrera-Viedma, E. Building consensus in group decision making with an allocation of information granularity. Fuzzy Sets Syst. 2014, 255, 115-127. [CrossRef] 
38. Cabrerizo, F.J.; Morente-Molinera, J.A.; Pedrycz, W.; Taghavi, A.; Herrera-Viedma, E. Granulating linguistic information in decision making under consensus and consistency. Expert Syst. Appl. 2018, 99, 83-92. [CrossRef]

39. Khiat, S.; Djamila, H. A temporal distributed group decision support system based on multi-criteria analysis. Int. J. Interact. Multimed. Artif. Intell. 2019, 5, 7-21. [CrossRef]

40. Taibi, A.; Atmani, B. Combining fuzzy AHP with GIS and decision rules for industrial site selection. Int. J. Interact. Multimed. Artif. Intell. 2017, 4, 60-69. [CrossRef]

41. Yu, L.P.; Zeng, S.Z.; Merigo, J.M.; Zhang, C.H. A new distance measure based on the weighted induced method and its application to Pythagorean fuzzy multiple attribute group decision making. Int. J. Intell. Syst. 2019, 34, 1440-1454. [CrossRef]

42. Zeng, S.Z.; Mu, Z.; Balezentis, T. A novel aggregation method for Pythagorean fuzzy multiple attribute group decision making. Int. J. Intell. Syst. 2018, 33, 573-585. [CrossRef]

43. Zhang, C.H.; Chen, C.; Streimikiene, D.; Balezentis, T. Intuitionistic fuzzy MULTIMOORA approach for multi-criteria assessment of the energy storage technologies. Applied Soft Comput. 2019, 79, 410-423. [CrossRef]

44. Zeng, S.Z.; Chen, S.M.; Kuo, L.W. Multiattribute decision making based on novel score function of intuitionistic fuzzy values and modified VIKOR method. Inf. Sci. 2019, 488, 76-92. [CrossRef]

45. Zhang, C.H.; Wang, Q.; Zeng, S.Z.; Balezentis, T.; Streimikiene, D.; Alisauskaite-Seskiene, I.; Chen, X. Probabilistic multi-criteria assessment of renewable micro-generation technologies in households. J. Clean. Prod. 2019, 212, 582-592. [CrossRef]

(C) 2020 by the authors. Licensee MDPI, Basel, Switzerland. This article is an open access article distributed under the terms and conditions of the Creative Commons Attribution (CC BY) license (http://creativecommons.org/licenses/by/4.0/). 